\title{
A CONSTRUÇÃO DA INTELIGÊNCIA EMOCIONAL DE MULHERES ENCARCERADAS NA CIDADE DO RECIFE
}

\section{LA CONSTRUCCIÓN DE LA INTELIGENCIA EMOCIONAL DE MUJERES ENCARCELADAS EM LA CIUDAD DE RECIFE}

DOI: http://dx.doi.org/10.5965/1984317815022019268

Maria Sandra Montenegro Silva Leão

Universidade Federal de Pernambuco sandra.montenegro@yahoo.com.br

\author{
Silvana Cristina Freire \\ Rede Estadual de Ensino de Pernambuco \\ silcris csf@hotmail.com
}

Sebastiana Célia do Nascimento Rede Estadual de Ensino de Pernambuco sebastianaceliadonascimento@gmail.com

\section{RESUMO}

Trata-se de uma pesquisa qualitativa descritiva e exploratória realizada em uma penitenciária feminina do Recife. O objetivo foi compreender se a educação ofertada através da modalidade EJA possibilitava a construção da inteligência emocional nas mulheres encarceradas. Os materiais e métodos foram a observação e entrevistas para tecer uma compreensão através das falas das participantes da pesquisa. A pesquisa contou com seis participantes. Os dados foram analisados conforme a técnica de Análise de Conteúdo. Os resultados obtidos demonstram que a educação vivenciada no ambiente prisional colaborou para a melhora de três características da inteligência emocional: empatia, auto-estima e controle de impulsividade. Apreendeu-se que para as entrevistadas o estudo é importante porque ameniza o sofrimento, minimiza a solidão e ensina a tornar-se uma pessoa melhor.

Palavras-Chave: Inteligência emocional. Educação. Mulheres encarceradas.

\section{RESUMEN}

Esta es una investigación cualitativa, descriptiva y exploratoria, realizada em uma prisão feminina em Recife. El objetivo fue averiguar si la educación ofrecida a través de la modalidad educativa EJA permitía la construcción de inteligência emocional en mujeres encarceladas. Los materiales y métodos fueron observaciones y entrevistas para tejer una comprensión a través de los discursos de las participantes de la investigación. La encuesta incluyó seis participantes. Los datos se analizaron de acuerdo com la técnica de análisis de contenido. Los resultados obtenidos demuestran que la educación experimentada en el entorno penitenciario contribuyó a la mejora de tres características de la inteligencia emocional: empatía, autoestima y control de la impulsividad. Se entendió que para los entrevistados el estudio es importante porque alivia el sufrimiento, minimizar la soledad y enseña cómo convertirse en una mejor persona.

Palabras clave: Inteligencia emocional. Educación. Mujeres encarceladas. 


\section{INTRODUÇÃO}

Este artigo apresenta os resultados de uma pesquisa em uma Colônia Penal Feminina, na modalidade Educação de Jovens e Adultos recebida por um grupo de mulheres encarceradas contribuiu para construção da inteligência emocional. É um trabalho que se apoia na perspectiva das Epistemologias do Sul, proposta pelo sociólogo Boaventura de Sousa Santos (2019) por ter como princípio o diálogo com outros saberes, trazer à superfície os silenciamentos e sofrimentos de grupos minoritários em múltiplas culturas e contextos geográficos.

A partir desta posição política, entendemos que o sistema prisional se constitui em um espaço geográfico dentro de outro espaço chamado Brasil. O sistema prisional é um local muito peculiar dentro de um outro Brasil: saberes que desconhecemos, em termos de modos de viver e de falar sobre a vida, é um mundo com necessidades de mobilizar o direito, a justiça e as condições básicas de sobrevivência.

Em um universo de 34.058 mulheres presas no Brasil, representando cerca de $7 \%$ do total da população penitenciária do país (BORGES, 2019), predominando um perfil de mulheres jovens, negras e provenientes de ambientes pobres, esquecidos pelas políticas públicas, fomos motivadas a desejar entender como são as práticas educativas vivenciadas na Colônia Penal Feminina do Bom Pastor, na cidade de Recife.

Reconhece-se que ambiente carcerário possui precárias condições de vida, principalmente porque mulheres e homens parecem perder a condição de ser humano, deixam de fazer parte do mundo, vão sendo esquecidos paulatinamente. Entretanto, nosso impulso foi o de buscar entender aquele mundo, considerado 'estranho', 'cheio de pessoas ruins' e que devem receber todos os castigos possíveis conforme o falar do senso comum, ideias presentes em noticiários e em conversas com pessoas do nosso cotidiano.

Partindo destas constatações, o objetivo geral da pesquisa foi identificar se e quais práticas pedagógicas contribuem para o desenvolvimento da inteligência emocional de mulheres encarceradas. 
Entendemos a prática educativa sendo integrativa, considerando a organização de situações diversas, priorizando o cuidado com a vida do ser humano, lidando com diversas dimensões humanas: cognitiva, corporal, mental, emocional, relacional, espiritual, dentre outras. Neste sentido, elegemos o tema 'inteligência emocional' e elaboramos as questões: é possível a educação escolar desenvolver uma melhora na inteligência emocional de mulheres encarceradas? O que essas mulheres narram sobre sua possível transformação? Qual a diferença que a educação escolar produziu em si mesmas?

O suporte teórico sobre inteligência emocional se amparou nos contributos da produção de Daniel Goleman (1996, 2006), Howard Gardner (1993, 1995) com seus estudos sobre a teoria das inteligências Múltiplas, porém, neste caso, nos detivemos na Inteligência Intrapessoal e Interpessoal, que são complementares para o processo de socialização, de equilíbrio emocional e autoconhecimento. Outros autores foram relevantes para compreendermos a importância de aplicar sentidos à nossa situação, aos nossos questionamentos e a valorização dos seres humanos, por exemplo, Sousa Santos, (2019); Varella, (2017), Foucault ( 2009) e Borges, (2019).

Realizamos uma busca no Banco de Teses da CAPES, verificamos que, até o momento do levantamento da literatura especifíca havia cento e setenta e oito artigos relacionados ao tema inteligência emocional em diversas áreas, mas não dialogavam com a problemática da educação no cárcere. Buscamos o tema, relacionando-o a mulheres encarceradas e encontramos nove artigos envolvendo educação em presídios femininos, elencamos abaixo os textos encontrados:

1) Panorama da estrutura presidiária brasileira, tendo como autores Cartaxo e Cavalcanti (2013);

2) O significado e a vivência do abandono familiar para a presidiária, da autoria de Jesus, Oliveira e Brandão (2015);

3) Relato de experiência na educação carcerária (CARLOS TEIXEIRA, 2007);

4) Gênero e Prisão: o encarceramento de mulheres no sistema penitenciário, de Hélio Branstein (2009); 
5) Os filhos do governo: a formação da identidade criminosa em crianças órfãs e abandonadas (ROBERTO SILVA, 1997);

6) Narrativas de mulheres na prisão sobre ser mulher, da autoria de Márcia Cavalcanti (2007);

7) Relações parentais de mulheres presidiárias, de Sílvia B. Machado (2010);

8) A educação de adultos presos, de Manoel Português (2001);

9) A ressocialização no sistema carcerário feminino, de Talita Pereira (2010)

Os artigos acima contribuíram para entendermos as semelhanças e diferenças entre os estudos apresentados nos textos, que estão devidamente inclusos nas referências e as situações percebidas, vivenciadas e estudadas por nós durante o período de desenvolvimento da pesquisa. Entretanto, considerando a perspectiva de Sousa Santos (2019) optamos pela escuta das mulheres encarceradas, uma vez que estão no lugar onde predomina o silenciamento. É nossa intenção trazer suas falas, considerando os seus saberes.

Apresentamos a seguir, o problema de pesquisa, as bases teóricas, os caminhos metodológicos, as considerações finais do trabalho constatando a existência de muita denúncia em relação as condições das pessoas encarceradas, mas um grande descompasso das políticas públicas em atender a situação dos grupos excluídos, encarcerados ou não.

\section{APORTES TEÓRICOS DA PESQUISA}

Em tempos de incertezas e desigualdades crescentes demonstradas através dos dados do Instituto Brasileiro de Geografia e Estatística (2019), salta aos olhos o empobrecimento da população através do crescente desemprego, dos subempregos, da quebra dos direitos sociais, da queda do produto interno bruto, o desmonte da saúde pública e da educação enquanto serviços essenciais à população mais pobre. Ao mesmo tempo, se fortalece um discurso letal para vários segmentos sociais: 'bandido bom é bandido morto', contrariando a ideia de vivermos em uma sociedade 
mais justa, mais humanizada, menos desigual, mas sabendo conviver com a diversidade cultural, racial, étnica, de gênero, de credos religiosos, dentre outras características que nos tornam unos e diferentes simultaneamente.

Apesar de muitos estudos apontarem a necessidade de revisão do modelo prisional brasileiro, constatamos que a frágil política pública governamental, considerando a saúde, a educação e as condições de vida na prisão são quase inexistentes. Hoje, parte da sociedade civil clama pela pena de morte, pela volta dos castigos corporais; observa-se grandes grupos de pessoas praticando a justiça com as próprias mãos. Os jornais cotidianos estão repletos de notícias com este teor. Os trabalhos científicos sobre as condições de vida nas prisões atestam o fortalecimento da violência, da falta de condições mínimas para a sobrevivência dentro do ambiente carcerário e a necessidade urgente de se rever as políticas públicas para este segmento da população, conforme demonstram as pesquisas de Cartaxo e Cavalcanti (2013), Varella (2017), dentre outros.

A partir da constatação da predominância de um modelo punitivo e pretensamente disciplinar, assim como de uma investigação realizada em outra pesquisa sobre o papel da educação na ressocialização de mulheres encarceradas, surgiram as questões que nortearam esta pesquisa: a educação vivenciada no ambiente carcerário contribui para desenvolver alguns aspectos da inteligência emocional em mulheres que estão encarceradas? O que dizem estas mulheres a respeito deste tema? Como expressam suas emoções a respeito da educação recebida no cárcere e seus contributos para a melhora de sua auto imagem?

Tomamos como pressuposto que o equilíbrio das emoções permite desenvolver sentimentos de empatia, de responsabilidade, compromisso consigo mesmo, com os outros, maior serenidade para enfrentar conflitos do cotidiano, apesar das adversidades.

Neste sentido, a educação formal não deve ter a pretensão de tudo resolver no âmbito do que é humano, mas se constitui em um devir, e oferecer condições para o amadurecimento e autonomia do sujeito. Educar deve ter o sentido pleno de acreditar 
na educabilidade de todos os seres humanos, independente de sua condição existencial. Assim, o professor exerce um papel preponderante nesta direção porque o seu trabalho possibilita a arte do encontro com o outro ser diante de si.

\subsection{A construção da inteligência emocional e as condições existenciais}

A construção da inteligência emocional não está desatrelada das condições de vida dos sujeitos, principalmente se estamos nos referindo a mulheres negras, pobres, analfabetas e oriundas de comunidades carentes. Conforme Borges (2019), "o Brasil tem uma população prisional que não para de crescer [...] temos a terceira maior população prisional do mundo, ficando atrás de Estados Unidos e China (p.18)". Na continuidade de sua análise, Borges (2019) demonstra que $72 \%$ da população carcerária feminina em São Paulo é composta de mulheres negras. Esta autora denuncia que duas em cada três mulheres presas são negras, portanto, existe, de fato, a penalização do gênero feminino, especialmente com mulheres negras.

No Estado de Pernambuco, em 2018, houve um total de 228 assassinatos de mulheres, e Pernambuco ocupa o sétimo lugar entre os estados brasileiros com o maior número de assassinato de mulheres. O percentual de assassinatos por feminicídio foi de 32,9\%. Dos 228 assassinatos de mulheres, a maioria era de pessoas negras ou pardas (PORTAL PERNAMBUCO, 2019). Isto reitera a ideia de que a violência está por dentro do contexto social, disseminando a percepção da mulher como um objeto que pode ser descartado. O modelo histórico patriarcal tem predominado em nossa sociedade, apesar dos avanços nas lutas feministas, e também reflete o modelo neoliberal que preconiza a retirada de direitos sociais, nega a diversidade das lutas pela dignidade, rejeita o protagonismo de grupos excluídos política e socialmente. O capitalismo neoliberal cria discriminações e exclusões ao privilegiar os direitos das classes sociais com grande poder econômico e com laços de apoio político aos grupos que ocupam o poder no âmbito do Estado.

Parte da humanidade está exposta ao sofrimento da fome, o medo da violência, a ausência de políticas públicas que proporcionem condições mínimas para viver. Um 
ponto crucial deste problema é a educação pública, esteja a escola situada em ambientes livres ou em ambientes carcerários.

A prisão ainda funciona como um aparelho que possibilita um saber sobre os apenados e um poder disciplinar através do controle, da vigilância e da hierarquização dos indivíduos em relação uns aos outros. Foucault (2002) destaca que a prisão está ligada a ascensão da burguesia, que gerou uma sociedade disciplinar, na qual toda a população, carcerária ou não, passa a se guiar por regras estabelecidas de coesão e coerção. Nesse sentido o encarceramento surgiu a partir de um novo discurso: defender os cidadãos de bem, recuperar os infratores e devolvê-los recuperados ao convívio social. Foucault (2009) também destaca que as técnicas corretivas não tinha e continua a não ter a finalidade de melhorar os indivíduos, mas o de forjar a obediência a qualquer custo.

Seguindo o raciocínio de Foucault (2009), ou seja, se a reclusão não consegue humanizar a punição, quais as perspectivas da Educação de Jovens e Adultos para as mulheres encarceradas? Em primeiro lugar, a educação escolar é um direito garantido por Lei, conforme artigo 207, da Constituição Federal do Brasil. Em segundo lugar, embora não garanta a ressocialização, traz possibilidades de gerar esperanças e contribuir para mudanças nas diversas maneiras das encarceradas perceberem a si mesmas e a vida. Por este caminho, chegamos aos estudos de Daniel Goleman (2006), este autor desenvolveu uma densa pesquisa onde demonstra que a Inteligência emocional pode ser construída, desde que tenhamos condições de integrar o pensar, o fazer e o agir por diversos meios, dentre estes, a educação. Inteligência Emocional é a combinação das competências sociais - capacidade de se conectar com a sociedade- e a competência pessoal enquanto capacidade de se conectar de maneira harmônica consigo mesmo.

No quadro abaixo elencamos as características definidoras de inteligência emocional. 


\begin{tabular}{|c|c|}
\hline \multicolumn{2}{|c|}{ Característica de uma pessoa inteligente emocionalmente } \\
\hline 1-Conhece suas emoções & $\begin{array}{l}\text { Conhece, analisa suas } \\
\text { ações e emoções em reposta ao } \\
\text { estímulo recebido. }\end{array}$ \\
\hline 2-Sabe lidar com as emoções & $\begin{array}{l}\text { Aprende a lidar com a } \\
\text { emoção e se mantêm equilibrada } \\
\text { os momentos de tensão. }\end{array}$ \\
\hline 3- Automotivação & $\begin{array}{l}\text { Sua motivação não vem de } \\
\text { algo externo. Agi de maneira } \\
\text { consciente. }\end{array}$ \\
\hline 4-Empatia & $\begin{array}{l}\text { Sabe se colocar no lugar do } \\
\text { outro e reconhece emoções e } \\
\text { comportamentos. }\end{array}$ \\
\hline $\begin{array}{l}\text { 5- sabe relacionar-se } \\
\text { interpessoalmente }\end{array}$ & $\begin{array}{l}\text { Sabe ter boas relações e } \\
\text { guia as emoções dos outros } \\
\text { criando um ambiente positivo em } \\
\text { sua volta. }\end{array}$ \\
\hline 6. Gestão do estresse & $\begin{array}{l}\text { Controlar os níveis de } \\
\text { estresse ruim e gerar mudanças } \\
\text { em si }\end{array}$ \\
\hline 7. Controle de impulsividade & $\begin{array}{l}\text { Controlar a impulsividade e } \\
\text { saber adiar as satisfações. }\end{array}$ \\
\hline 8. Autoestima & $\begin{array}{l}\text { Ter uma boa avaliação de si } \\
\text { mesma enquanto pessoa ver } \\
\text { qualidades em si. }\end{array}$ \\
\hline
\end{tabular}

FONTE: Inteligência Emocional (GOLEMAN, 1996)

Enquanto a inteligência social consolida a importância dos relacionamentos construtivos para interações mais saudáveis, a inteligência intrapessoal se fortalece interiormente (GARDNER, 1993).

\section{2 - Procedimentos Metodológicos}


Nesta pesquisa, utilizamos a investigação qualitativa por causa do papel transformador e político da Educação nas sociedades contemporâneas. Mais do que conhecer fragmentos do real, as linguagens qualitativas permitem identificar o comum sob a aparência de heterogeneidade, possibilitam sistematizar sem neutralizar a singularidade e permitem articular níveis de intervenção distintos. A investigação qualitativa não se baseia em uma única concepção teórica ou metodológica, enquadra diversas abordagens, como sejam a etnografia, a fenomenologia ou o construtivismo.

Sem pretendermos explorar as diversas nuances da pesquisa qualitativa, consideramos que a compreensão da realidade pressupõe panoramas de leituras diferenciadas e combinadas de forma coerente. A partir do que foi explanado, reafirmamos a relevância das investigações qualitativas facultarem um grau relativo de inteligibilidade aos fenômenos sociais e humanos.

\section{1 - Contexto de realização da pesquisa}

Para uma melhor compreensão da pesquisa desenvolvida, esclarecemos alguns elementos:

A - O local de pesquisa foi a Colônia Penal Feminina do Bom Pastor, localizada na cidade do Recife. Até o término desta pesquisa havia um total de 665 mulheres encarceradas, mas com capacidade de lotação de apenas 150 pessoas. Naquele momento, 405 mulheres estavam em prisão provisória. Embora a Lei № 7.960, de 21 de dezembro de 1989 estabeleça o máximo de 81 dia de prisão provisória, mais de $70 \%$ das mulheres encarceradas ultrapassavam em mais de 200 dias o tempo na prisão. A explicação para esta condição era a lentidão da justiça, a pouca disponibilidade de assistência jurídica pública, as precárias condições econômicas das famílias das mulheres em situação de privação de liberdade, isto impossibilitava a contratação de advogados particulares. Além da frágil condição econômica das famílias e das mulheres encarceradas, existe o desconhecimento dos direitos, de como agir, a quem recorrer em situações deste nível de gravidade. 
B - O governo do Estado de Pernambuco tem um programa de ressocialização para as pessoas em privação de liberdade. É o Plano Estadual de Educação em Prisões de Pernambuco (PE, 2012). É um plano que estabelece três objetivos: desenvolver uma educação com função reparadora, função equalizadora e função qualificadora (p.16). Portanto, a Educação de Jovens e Adultos do Ensino Fundamental e do Ensino Médio é compreendida como o meio para se atingir os objetivos acima descritos.

C - No panorama interno da Colônia Penal Bom Pastor o desenvolvimento da educação tem como prioridade a ressocialização, embora seja um termo polissêmico e sem consenso sobre o que vem a significar ressocializar, como realizar a prática de ressocialização. Socializar por quê? Para quê? Quem deve ser socializado? São questões que esta investigação não se deteve, mas que estão na ordem dos debates no campo das políticas públicas para as instituições prisionais, na área da Educação, do Serviço Social, da Psicologia, das ciências humanas em sua totalidade.

A Escola da Colônia Prisional Bom Pastor atende em torno de 50 mulheres, entretanto, não existe uma frequência regular, não é obrigatória. A frequência é em torno de 25 mulheres para os dois turnos: manhã e tarde. É uma frequência baixa devido a vários fatores: adoecimento, desinteresse, baixa perspectiva sobre o valor da aprendizagem para a vida, castigos por desobediência. Somando estes itens que foram identificados aos que não pudemos identificar, é possível inferir que tanto a dinâmica institucional quanto as expectativas das mulheres quanto ao valor da educação escolar são bem baixas. A escola se chama Olga Benário, recebe materiais para os estudos (cadernos, lápis, giz) e os professores são concursados efetivos. O motivo central da participação de apenas seis mulheres foi a situação de baixa frequências as aulas, assim como aceitaram participar das entrevistas com regularidade.

\section{2 - A preparação para a coleta de dados}


Antes da elaboração dos instrumentos de coleta de dados, tivemos duas reuniões com duas professoras, uma do horário da manhã e outra do horário da tarde. Nossa intenção era receber o maior número possível de informações sobre o perfil das turmas e sobre os procedimentos pedagógicos e como iriam trabalhar a construção da inteligência emocional em sala de aula. As professoras enfatizaram que iriam vivenciar algumas tarefas em grupo, visando trabalhar em uma perspectiva freireana, cujo teor seria a paz social e pessoal.

Preparamos três entrevistas, a primeira com a intenção de nos apresentarmos enquanto pesquisadoras e apresentarmos os objetivos do trabalho, a segunda e a terceira objetivavam compreender se a educação escolar estava possibilitando construir algum nível de inteligência emocional nas mulheres encarceradas. Em nosso entendimento, a inteligência emocional pode ser um fator importante para melhorar as relações humanas, especialmente dentro de ambientes complexos, de difícil convivência, por exemplo, as instituições prisionais. Ao mesmo tempo, a inteligência emocional, trabalhada por dentro das escolas tem potencial para desenvolver a consciência de si mesmo, do seu papel no jogo da vida, entendendo as razões políticas, sociais que contribuem para o entendimento de quem somos.

Foram doze horas o total de entrevistas. Em relação as observações, registramos nove horas na totalidade. Priorizamos observar: as atitudes das estudantes em relação aos conteúdos: participavam ativamente das aulas? Frequentavam regularmente? Predominava uma boa interação entre estudantes e professoras? Como reagiam as diferenças de opinião? As salas de aulas são compostas por um quadro a giz, uma mesa para a professora, trinta cadeiras com braço para as estudantes e uma estante de ferro para guardar materiais escolares, as atividades elaboradas pelas estudantes e algumas cartolinas. As paredes possuem uma cor desbotada, três cartazes colados com frases motivacionais. As professoras às vezes trazem revistas para atividades com colagens. 
De um modo geral, as estudantes gostam de cantar e as professoras aproveitam para retirar frases e trabalhar alguns aspectos gramaticais ou o sentido que a letra tem para o grupo.

\section{3 - A aplicação dos instrumentos de coleta de dados}

Para a construção dos instrumentos, orientamo-nos pelo foco central da pesquisa que buscou identificar se a educação proposta no ambiente carcerário da Colônia Penal do Bom Pastor possibilitava a construção de inteligência emocional nas mulheres encarceradas. Adotamos as siglas PPL1, PPL2, PPL3, PPL4, PPL5 e PPL6 significando Pessoa Privada de Liberdade, esta medida garante o anonimato das nossas interlocutoras. As participantes da pesquisa estavam matriculadas e cursando a Educação de Jovens e Adultos nas fases I, II, III e IV.

A primeira entrevista foi realizada com o grupo de mulheres reunidas, as demais entrevistas foram individualizadas, gravadas, e elaboramos um roteiro inicial, todavia sofreram alterações à medida que as falas se desenvolviam. As observações foram organizadas previamente, mas outras questões surgiram durante o processo das aulas. O trabalho de campo para aplicação dos instrumentos para coleta de dados aconteceu entre os meses de maio a novembro de 2018. As seis mulheres assinaram um Termo de Consentimento Livre e Esclarecido, conforme preconizado pela Resolução №. 466/2012, que normatiza as pesquisas com seres humanos.

A categoria central de análise é Inteligência Emocional, situada no processo de Educação de Jovens e Adultos, dentro de um presídio feminino. Entretanto, não deixamos de observar a situação física, humana e social do presídio, e como o Estado, enquanto esfera de governo responde as necessidades e carências deste local de profunda complexidade: a Colônia Penal do Bom Pastor.

\section{3 - ANÁLISE E INTERPRETAÇÃO DOS DADOS}

\section{1 - O perfil social das participantes da pesquisa:}


Apresentaremos neste tópico recortes do material coletado, uma vez que, por ser um artigo, impede a totalidade das falas e das observações. As entrevistadas estavam em uma faixa etária entre 21 e 45 anos. A maioria estudou em escolas públicas, mas não concluiu o Ensino Fundamental. As entrevistadas são negras, sem profissão formal. Duas dessas mulheres trabalhavam fazendo faxinas sem carteira assinada, uma se dedicava apenas a tomar conta do lar, e três entrevistadas trabalhavam como camelôs. Vendiam almoço perto de edifícios em construções, saladas de frutas em pontos de ônibus coletivos e em portas de escolas públicas. A renda financeira, segundo as participantes, variava entre 300,00 e 400,00 reais por mês. Não possibilitava pagar todos os compromissos da casa, mas ajudava.

A desigualdade financeira estava presente na vida que levavam, uma vez que não recebiam ajuda de seus familiares ou cônjuges. Sempre residiram em locais carentes de serviços públicos: luz, saneamento básico, ruas asfaltadas, postos de saúde.

Constata-se a predominância de uma vida de pobreza causada pela negligência da ausência de políticas públicas, condenadas a viver aprisionadas numa condição de paralisia social, em outras palavras, vida condenada à miséria e com poucas chances de sair desta situação, apesar dos discursos inflamados sobre o valor da meritocracia.

Ao mesmo tempo, as pessoas que vivem em comunidades pobres, expulsas dos direitos sociais, carregam o estigma da culpa. Vivemos um tempo de proliferação do idêntico, "a dialética da violência impera em geral: um sistema que rejeita a negatividade do diferente desenvolve traços auto destrutivos" (CHUL-HAN, 2018, p.9). Nesta direção a Educação de Jovens e Adultos dentro do sistema prisional, traz como proposta diminuir os processos de violência física e simbólica que acontecem por dentro das prisões, entretanto, essa violência está disseminada por todo o ambiente carcerário, não é um fenômeno que se origina apenas nos encarcerados

A partir da V Conferência Internacional de Educação de Adultos, em 1997, o Tema VIII reconhece o direito dos detentos à aprendizagem: "elaborando e pondo em 
marcha, nas prisões, amplos programas de ensino, com a participação dos detentos, a fim de responder às suas necessidades e aspirações em matéria de educação" (CONFITEA, 1997, p. 134). Se consolida, desde então, a Educação no Cárcere para Jovens e Adultos. Na Colônia Penal feminina investigada é denominada de Pedagogia da mansidão, o que iremos abordar em prosseguimento.

\section{1 - A pedagogia da mansidão}

O mundo na sala de aula se constituía de um currículo bem diversificado, tendo como referência pedagógica o pensamento do educador brasileiro Paulo Freire, trazendo a perspectiva da esperança, da educação para a paz e do trabalho coletivo enquanto caminho para a solução de conflitos comuns a todas. A partir desta percepção, as atividades de aprender a ler, a interpretar, a escrever e a "fazer contas" eram elaboradas a partir de temas geradores, nascidos das experiências de vida das mulheres encarceradas, assim como da criatividade da professora do Ensino Fundamental. Além destas atividades, havia a roda de conversa - semanalmente as mulheres se reuniam em um grande grupo para troca de experiências; havia a atividade intitulada Rol de ideias para melhorar a vida. Nesta atividade predominava a tempestade de ideias, com a intenção de trazer soluções para a vida coletiva na prisão. Por último, havia o tema relações intra e interpessoais na prisão: caminhos e escolhas.

Este último foi o tema escolhido para observar com mais frequência, pois se relacionava com a questão de pesquisa. A proposta em aula era que as estudantes falassem sobre a relevância das pessoas do cárcere, funcionários, colegas, direção. Como interagiam, como estabeleciam laços de amizades, como resolviam conflitos, se perderam amizades na prisão e as razões para isto ter acontecido, dentre outras. Em vários momentos aconteciam episódios quase catárticos, se desenvolvia uma espécie de psicodrama com falas de acusações contra colegas, contra funcionários, contra a família; havia falas de raiva contra si mesma, das escolhas que fez, e até mesmo falas que culpavam o destino. 
Cada um nasce com um destino. Não adianta fugir. Você tenta fazer o certo, ser bom, não adianta. Uns nasce (sic) para viver no bom e outros vão batalhar de outro jeito, até que a ruindade aparece (PPLO4).

Você já viu alguém mudar o que era para ser seu? Seja bom ou ruim, o que é do homem o bicho não come. Pode rezar sem parar, mas destino é também uma prisão (PPL02)

Apesar do esforço da professora em discutir aspectos que podemos melhorar em nós mesmos, percebemos a existência de uma pressão destrutiva sobre o outro vinda desta tecnologia de disciplinamento do ser humano, da vigilância do comportamento e individualização dos elementos do corpo social (FOUCAULT, 2009) contribuindo para que o sentimento de culpa seja apenas dele, distante da reflexão sobre as condições externas que colaboraram para o absurdo das situações que asfixiam o outro em supostas situações de escolhas:

Eu sinto vergonha das coisas que eu fiz. Eu deixei um rastro que não foi bom. Quando eu fui presa, os policiais entraram na minha casa, me algemaram, disseram coisas horríveis com a minha mãe e meus filhos presenciaram toda a cena, ficaram gritando, querendo me abraçar e eu também assustada e chorando. O mundo do crime não tem nada de bom pra dá (sic), não compensa. Dinheiro e fama não trazem nada, só inimizade, intriga e ódio (PPL2, 2018)

Ao longo do processo de aprendizagem na escola da Colônia Penal, a partir da adoção de algumas estratégias da professora da sala para trabalhar os aspectos emocionais das educandas esta participante da pesquisa demonstrou melhoras na diminuição da culpa. As atividades predominantes eram rodas de conversas sobre experiências, memórias das coisas boas que fizeram para si e para os outros, imaginando um futuro melhor, buscando retirar de suas consciências a ideia de que cada pessoa nasce com uma natureza boa ou má. Em outro momento, a participante PPL2 relatou: "me sinto mais aliviada quando faço de roda de conversa, não tem julgamento de quem eu sou, a culpa vai morrendo, mas eu sei que fiz o errado, mas eu não sou só o erro". 
Em um outro momento a professora solicitou uma atividade que escrevessem em um pedaço de papel, uma palavra de como se sentiam quando suas necessidades não estavam sendo atendidas. Das 18 mulheres que estavam em aula, a palavra mais repetida em primeiro lugar foi 'ABANDONADA', em segundo lugar, DESESPERADA, e em terceiro lugar destacou-se a palavra PESSIMISTA. Dentre as mulheres que participaram desta pesquisa, predominaram as palavras 'desesperada e pessimista'.

As expressões revelam os sentimentos predominantes e que dificultam a construção de uma inteligência emocional quando se constata a derrocada do estado de bem estar social somados aos problemas de habitabilidade na prisão, pois conforme relatado acima, a superpopulação carcerária e o rotineiro tempo na prisão causam danos mentais, emocionais e físicos.

Apesar da constatação dos sofrimentos dentro do sistema prisional, a escola possui vários sentidos para essas mulheres: uma aluna narrou que não gosta de perder aula, nunca havia ido à escola, agora tem aproveitado para aprender a escrever seu nome e poder assinar os documentos que o advogado traz pra ela:

Eu participo da escola, para mim é a melhor coisa que aconteceu comigo, foi eu ter entrado na escola pra (sic) estudar. Eu nunca estudei quando eu era criança. Quando eu entrei aqui eu nem sabia escrever meu nome e agora já sei. Meu advogado agora me dá os papeis e eu assino meu nome (PPL 1).

Uma outra aluna, ao ser questionada se gostava de alguma atividade educacional, de como ela se sentia na aula, respondeu: "participo da EJA, para aprender e esquecer os problemas lá de fora e de estar aqui dentro, mas não tenho muito interesse" (PPL5).

É compreensível que haja um nível de desinteresse na escola devido a escassez de perspectivas sociais, de projetar um futuro com condições de trabalhar para sustentar a família. Considerando que a Lei determina a socialização e a realidade consolida o criminoso, as respostas das mulheres participantes da pesquisa estão coerentes. Para nossa questão de pesquisa: é possível construir algum nível de 
inteligência emocional em mulheres encarceradas? Não deixamos de observar as condições de história de vidas e da intenção quase impossível das prisões: privar a liberdade do outro e transformá-lo em alguém melhor.

Perguntamos se estão percebendo uma reeducação interna, uma melhora em relação aos seus impulsos (as seis mulheres possuem um histórico de causadoras de brigas), uma delas afirmou que ainda não se sente em condições de sair da prisão: "Eu não tenho pressa de sair daqui agora. Eu estou bem mais segura aqui. Lá fora está pegando fogo! Quando eu e meus amigos se juntavam era terrível" (PPL6). Posteriormente, revela que “ainda não tem forças suficientes para dizer 'não' as drogas, nem as amizades que a levam para o vício e o furto. Declarou que seu grupo tem muita influência, e na vida marginal é ela que vai de frente porque tem uma boa conversa e envolve facilmente as vítimas.

Duas mulheres encarceradas analisam e dizem que estão preparadas para sair da prisão e afirmam que querem ter uma nova atitude, retomar a vida e reviver sua vida junto a sua família: "Percebo que hoje em dia estou pronta pra (sic) ir pra o mundo. No começo eu não estava pronta. Eu sei de tudo o que eu fiz de errado! Mas, quando eu sair daqui será tudo diferente, vou trabalhar e viver para meus filhos" (PPL4). "Eu já fiz besteiras demais, e olhe minha vida. Saindo daqui, tem que ter força de vontade para não repetir o errado" (PPL1)

Considerando as características da inteligência emocional construídas por Goleman (1996) e o resultado das observações e entrevistas das mulheres encarceradas ficam mais evidentes que houve uma melhora na autoestima, no controle da impulsividade e na autoestima. Ao término da pesquisa, constatamos empiricamente que, em sala de aula, as participantes da pesquisa estavam mais atentas ao conteúdo ensinado, interagindo melhor entre colegas e com alguns funcionários da Colônia, ajudando-se mutuamente, favorecendo o direito ao espaço de cada uma, com o propósito de alcançar melhores condições nos relacionamentos. 
Observamos a diminuição da quantidade de discussões, provocações e brigas físicas com colegas de classe, assim como uma percepção melhor de si mesmas:

Eu me sentia um lixo, tinha dias que nem sentia vontade de viver, é como se tanto fazia se vivia ou morria. Mas hoje penso diferente, eu sou gente, posso ser melhor do que já fui. Pensei tanto em morrer, pensava que ia para um outro inferno além desse aqui. Hoje não, eu comecei a ajudar um bocado de colegas aqui e elas gostam de mim, então eu não me sinto mais um lixo (PPL3)

Nunca me achei bonita, nunca gostei do meu cabelo, só vivia espichando ele (sic). Depois raspei a cabeça, fiquei meio doida. O tempo foi passando e vi que não era do cabelo que eu não gostava, era de mim. Aí fui para a aula, gostei das conversas, da matemática não gosto, não, e foi como uma nuvem indo embora dos meus olhos, fui vendo o que eu posso, o que eu devo fazer para enfrentar essa barra (PPL2)

É possível perceber um movimento de mudança no âmbito emocional, ainda de modo frágil, uma vez que os desafios dentro do sistema prisional são intensos, e ainda vigora um cenário de acriticidade e de baixa participação nas aulas. Aprender conteúdos curriculares é fácil, o maior desafio está no currículo oculto trazido da vida e das experiências dentro das prisões.

\section{CONSIDERAÇÕES FINAIS}

Ao analisarmos os relatos das mulheres entrevistadas, consideramos que a educação não resolve todos os problemas que enfrentam, mas pode fortalecer alguns aspectos essenciais para a vida: desenvolver a percepção dos direitos da pessoa, esteja ela encarcerada ou não; aprofundar o senso crítico em torno dos problemas sociais e do que provoca a desigualdade; pode habilitar a pessoa para argumentar e controlar impulsos prejudiciais ao diálogo; ensinar conteúdos curriculares propícios ao conhecimento da história, das artes, do espaço geográfico, da leitura, da escrita e da matemática articulados ao sentido da vida.

A escrita das narrativas destas mulheres encarceradas não deu conta de contemplar as experiências de vida, os medos que trazem, a busca incerta para se 
tornarem pessoas melhores. O objetivo da pesquisa foi alcançado, compreender se, e como a educação desenvolvida no ambiente carcerário feminino tem potencial para desenvolver a inteligência emocional. Consideramos que a inteligência emocional pode desenvolver o sentido da ética, reconhecendo o outro e a si mesmo enquanto sujeitos de direitos, e a educação de qualidade é um direito; é possível promover uma aprendizagem cognitiva e social.

Diante deste quadro, outros questionamentos surgiram: A proposta educativa denominada' pedagogia da mansidão' não é uma forma de ver o sujeito educado nos moldes burgueses do bom comportamento? É possível emancipar sem mudar as condições de vida das pessoas na prisão e ao sair dela? Quais as chances de reintegração? A melhora da inteligência emocional capacita a enfrentar a realidade fora da prisão?

São questões que ainda não podemos responder, mas acreditamos que a educação no ambiente carcerário deve permanecer, e que as mulheres encarceradas participem da elaboração do currículo escolar, é uma condição mínima de participação naquilo que diz respeito a elas.

\section{Referências}

BARDIN, Laurence. Análise de conteúdo. São Paulo: Edições 70, 1977

BRASIL, Ministério da Saúde. Resolução Nº 466/2012. Plano Nacional da Saúde no Sistema Penitenciário, Brasília, 2012

BRASTEIN, Hélio. Gênero e Prisão: o encarceramento de mulheres no sistema penitenciário. Anais do Congresso Internacional de Pedagogia Social. São Paulo, 2009. Disponível em http:// www.proceedings.scielo.br. Acesso em: 2 set de 2018

BORGES, Juliana. Encarceramento em Massa: feminismos plurais. São Paulo: Pólen, 2019

CARTAXO, Renata de Oliveira e CAVALCANTI, Alessandro. Panorama da Estrutura Presidiária Brasileira. Revista Brasileira de Promoção da Saúde, Fortaleza, n. 26: 266-273, abr.jun., 2013 
CAVALCANTI, Márcia. Narrativas de mulheres na prisão sobre ser mulher. Revista MEPAR, Recife, n. 05, v. 09, p. 125-208, jun/jul. 2007.

DECLARAÇÃO de Hamburgo sobre Educação de Jovens e Adultos. V CONFITEA. Hamburgo, jul.1997

FOUCAULT, Michel. Vigiar e Punir. Petrópolis: Vozes, 2009.

GARDNER, Howard. Inteligências Múltiplas. Porto Alegre: Artmed, 1993.

GARDNER, Howard. Inteligências Múltiplas a Teoria na Prática Escolar. Porto Alegre: Artes Médicas, 1995.

GOLEMAN, Daniel. Inteligência social: o poder das relações humana. Rio de Janeiro: Elsevier, 2006

GOLEMAN, Daniel, Inteligência emocional. Rio de Janeiro: Objetiva, 1996.

HAN CHUL-Byung. A Expulsão do Outro. Lisboa: Relógio d'agua, 2018.

JESUS, Amanda, OLIVEIRA, Lannuzya e BRANDÃO, Gisetti. O significado e a Vivência do abandono familiar para presidiárias. Revista Ciência e Saúde, Campina Grande, v 08, n. 25, p 19-25, maio/jun. 2015.

MACHADO, Sílvia. Relações parentais de mulheres presidiárias. São Paulo: Segmento, 2010

PERnAMBuco. Educação em Prisões de Pernambuco. Governo do Estado de Pernambuco. Recife: Gráfica Oficial do Estado, 2012.

PERNAMBUCO. Plano Estadual de Educação em Prisões de Pernambuco. Recife: Gráfica Oficial do Estado, 2012.

PEREIRA, Talita. A ressocialização no sistema carcerário feminino. Monografia do Curso de Especialização em Educação e Gestão. Recife: FAFIRE, 2010.

PORTUGUES, Manoel. A educação de adultos presos. Revista Educação e Pesquisa. São Paulo, v.27, n.2, p.355-374. Jul/dez.2001.

SANTOS, Boaventura de Sousa. Epistemologias do Sul. Coimbra: Almedina, 2019

SILVA, Roberto. Os filhos do governo: a formação da identidade criminosa em crianças órfãs e abandonadas. Revista Educação. São Paulo: Segmento, 1997. 
TEIXEIRA, Carlos. Relato de Experiência na Educação Carcerária. Revista Opinião, São Paulo, v. 12, n.37, p 20-29, nov/dez. 2007.

VARELLA, Dráuzio. Estação Carandiru. São Paulo: Companhia das Letras, 2017.

Recebido em 24 de abril de 2019 Aprovado em 27 de março de 2020 